\title{
Evaluation of pharmacological relaxation effect of the natural product naringin on in vitro cultured airway smooth muscle cells and in vivo ovalbumin-induced asthma Balb/c mice
}

\author{
YUE WANG ${ }^{1-3^{*}}$, YUN LU $^{1,3^{*}}$, MINGZHI LUO ${ }^{1}$, XIAOHAO SHI $^{1}$, \\ YAN PAN ${ }^{1}$, HUILONG ZENG ${ }^{1,3}$ and LINHONG DENG ${ }^{1-3}$ \\ ${ }^{1}$ Changzhou Key Laboratory of Respiratory Medical Engineering, Institute of Biomedical \\ Engineering and Health Sciences; ${ }^{2}$ School of Nursing; ${ }^{3}$ School of Pharmaceutical Engineering \\ and Life Science, Changzhou University, Changzhou, Jiangsu 213164, P.R. China
}

Received July 28, 2016; Accepted September 29, 2016

DOI: $10.3892 /$ br.2016.797

\begin{abstract}
Asthma has become a common chronic respiratory disease worldwide and its prevalence is predicted to continue increasing in the next decade, particularly in developing countries. A key component in asthma therapy is to alleviate the excessive bronchial airway narrowing ultimately due to airway smooth muscle contraction, which is often facilitated by a smooth muscle relaxant, such as the $\beta_{2}$-adrenergic agonists. Recently, bitter taste receptor (TAS2R) agonists, including saccharin and chloroquine, have been found to potently relax the airway smooth muscle cells (ASMCs) via intracellular $\mathrm{Ca}^{2+}$ signaling. This inspires a great interest in screening the vast resource of natural bitter substances for potential bronchodilatory drugs. In the present study, the relaxation effect of naringin, a compound extracted from common grapefruit, on ASMCs cultured in vitro or bronchial airways of Balb/c mice in vivo was evaluated. The results demonstrated that, when exposed to increasing doses of naringin $(0.125,0.25$, 0.5 and $1.0 \mathrm{mM}$ ), the traction force generated by the cultured ASMCs decreased progressively, while the intracellular calcium flux signaling in the ASMCs increased. When inhaled at increasing doses $(15,30$ and $60 \mu \mathrm{g})$, naringin also dose-dependently reduced the bronchial airway resistance of the normal and ovalbumin-induced asthma Balb/c mice in response to challenge with methacholine. In conclusion, these
\end{abstract}

Correspondence to: Professor Linhong Deng, Changzhou Key Laboratory of Respiratory Medical Engineering, Institute of Biomedical Engineering and Health Sciences, Changzhou University, 1 Gehu Road, Changzhou, Jiangsu 213164, P.R. China E-mail:dlh@cczu.edu.cn

${ }^{*}$ Contributed equally

Key words: naringin, bitter taste receptor agonist, airway smooth muscle relaxation, cell traction force, bronchial resistance, asthma therapy findings indicate that naringin was able to effectively relax murine ASMCs in vitro and in vivo, thus suggesting that it is a promising drug agent to be further investigated in the development of novel bronchodilators for the treatment of asthma.

\section{Introduction}

Asthma is a common chronic respiratory disease, affecting $>300$ million individuals worldwide, and its prevalence is rising, particularly in developing countries $(1,2)$. Approximately $8.3 \%$ of the US population suffers from asthma (3). Airway hyperresponsiveness (AHR) leading to excessive narrowing of the airways and, thus, causing dyspnea is considered to be the primary cause of asthma, though the mechanisms underlying AHR remain unclear (4). However, it is known that acute narrowing of the airway lumen is caused by contraction of the airway smooth muscle cells (ASMCs) (5-7). The counteracting therapy for AHR is, thus, to relax the ASMCs using bronchodilators. Currently, the most common bronchodilators are $\beta_{2}$-adrenoreceptor agonists; however, various issues have been raised regarding their use, such as tachyphylaxis and long-term safety. In addition, these agents are often ineffective in severe cases of asthma and can cause serious side effects, including abnormal heart rhythm and increased blood pressure in the patients $(8,9)$.

A study by Deshpande et al (10) discovered that human ASMCs express bitter taste receptors (TAS2Rs), and accordingly provide potential treatment of AHR using bitter substances. It has also been demonstrated that bitter substances, such as saccharin and chloroquine, are more effective in comparison with existing bronchodilators ( $\beta$ agonists) in terms of the extent of drug-induced relaxation of ASMCs. The relaxation mechanism of ASMCs induced by bitter substances is still debated; however, it is generally considered to involve the binding of bitter substance to TAS2Rs on the membrane of ASMC, causing membrane hyperpolarization and thus leading to localized intracellular calcium flux, namely $\left[\mathrm{Ca}^{2+}\right] \mathrm{i}$, responses $(8,10)$.

An important advantage of using bitter substances as bronchodilators is that they are vastly available in nature (8). Among them, the natural product naringin, a compound 
extracted from common grapefruit, is of great interest, as it is an effective bitter substance, and also widely available and relatively inexpensive. Previous studies have demonstrated that naringin is a flavanone with various bioactivities, including anti-inflammatory, expectorant and antitussive effects on asthma and acute lung injury $(11,12)$. However, those studies focused on airway inflammation, and the drug was administered orally. In the present study, we focused on the relaxation effect of naringin on ASMCs via inhalation, with the aim to evaluate this natural bitter substance as a potential bronchodilator for the treatment of AHR in asthma.

In order to study the in vitro and in vivo effects of naringin on ASMC relaxation, either cultured ASMCs were directly exposed to naringin solutions, or an ovalbumin (OVA)-induced asthma model of Balb/c mice was treated with aerosolized naringin via nasal inhalation. Subsequently, the traction force and the $\left[\mathrm{Ca}^{2+}\right]$ i generated by the cultured ASMCs were measured in the absence or presence of naringin. In addition, the airway resistance (Rrs) of the mice was evaluated in response to naringin inhalation.

\section{Materials and methods}

Chemicals and reagents. Naringin was purchased from Tokyo Chemical Industry Co., Ltd. (Tokyo, Japan). Collagen type I, anti-mouse IgG (Fab specific)-FITC antibody, 4',6-diamidino-2-phenylindole, Fluo-4, AM, and Pluronic ${ }^{\circledR}$ F-127 were purchased from Sigma-Aldrich (St. Louis, MO, USA). Cell culture reagents including Dulbecco's modified Eagle's medium (DMEM), 10\% fetal bovine serum (FBS), penicillin and streptomycin solution, were obtained from Thermo Fisher Scientific, Inc. (Waltham, MA, USA), unless stated otherwise.

Experimental animals. Female Balb/c mice ( $\mathrm{n}=55$; weight, 20-22 g; age, 6-8 weeks) were purchased from Cavens Laboratory Animal Co., Ltd. (Changzhou, China), an authorized supplier of experimental animals for use in medical research. The animals were maintained in a specific pathogen-free environment at room temperature $25 \pm 3^{\circ} \mathrm{C}$, relative humidity of $40-60 \%, 12$-h light/dark cycle and free access to food and water. All animal experiments were performed according to the Institutional Guidelines for Animal Care and Use Committee of Changzhou University (Changzhou, China). Adequate measures were taken to minimize the suffering of the experimental animals.

Isolation and in vitro culture of ASMCs from Balb/c mice. Primary ASMCs were isolated from Balb/c mice and cultured in vitro, as described previously (13). Briefly, the 6-8-week-old mice were anesthetized by intraperitoneal injection of pentobarbital sodium $(60 \mathrm{mg} / \mathrm{kg})$. The mice were dissected and the trachea was isolated. The isolated trachea was cleaned of connective tissues, sliced into small squares $\left(1 \times 1 \mathrm{~mm}^{2}\right)$, which were allowed to attach to the bottom of the flask. Subsequently, the tissue samples in the flask were placed in an incubator at $37^{\circ} \mathrm{C}$ with humidified air and $5 \% \mathrm{CO}_{2}$, until the cells migrated out of the tissue samples. Subsequently, the ASMCs were isolated according to their attachment time, and maintained in culture with DMEM containing 10\% FBS for
3-8 passages prior to use. The grown cells were verified as ASMCs by staining with antibodies against $\alpha$-smooth muscle actin [ $\alpha$-SMA (cat. no. BM0002; Wuhan Boster Biological Technology, Ltd., Wuhan, China); dilution, 1:1,000], as described in a previous study (14).

Assessment of traction force generated by cultured ASMCs. The traction force of cultured ASMCs was measured by the technique of Fourier transformation traction force microscopy using polyacrylamide substrate embedded with fluorescent microbead markers, as described previously (15-18). Briefly, the cultured cells were transferred to polyacrylamide gel dishes coated with type I collagen $(0.1 \mathrm{mg} / \mathrm{ml})$ at a density of 2,000 cells/dish in DMEM containing 10\% FBS and incubated for 12-24 h. After the cells were well adhered to the substrate, they were washed with phosphate-buffered saline and cultured in serum-free medium for $12 \mathrm{~h}$ prior to further investigation. Subsequently, control images of a single cell and of the fluorescent microbead markers were recorded by phase contrast and fluorescence microscopy, respectively. Increasing concentrations of histamine [0.01, 0.1 and $1 \mu \mathrm{M}$ (cat. no. 51-45-6); Aladin Industrial Corp., Shanghai, China], which served as a positive control, or naringin $(0.125,0.25,0.5$ and $1 \mathrm{mM})$ were then added to cell cultures sequentially at 3-min intervals, and fluorescent images of the microbead positions were recorded by fluorescence microscopy every $30 \mathrm{sec}$. When the treatments were completed, the cells were trypsinized and the cell-free bead positions were recorded as a reference point for bead displacement.

Assessment of intracellular $\left[\mathrm{Ca}^{2+}\right] \mathrm{i}$ in cultured ASMCs. Intracellular calcium signals were visualized as described previously $(19,20)$, using the membrane permeable $\left[\mathrm{Ca}^{2+}\right] \mathrm{i}$-sensitive fluorescent dye Fluo-4 acetoxymethyl ester (Fluo-4 AM). Briefly, cultured ASMCs were inoculated $\left(\sim 10^{4}\right.$ cells per dish) into confocal petri dishes with a glass bottom. Next, the cells were incubated with $5 \mu$ M Fluo-4 AM for $60 \mathrm{~min}$ at $37^{\circ} \mathrm{C}$ in a $5 \% \mathrm{CO}_{2}$ incubator. The cells were then washed with Tyrode's solution and incubated for $20 \mathrm{~min}$ to allow complete de-esterification of the cytosolic dye. The fluorescence intensity of the sample (Fluo-4-AM labeled ASMCs) was measured by laser scanning confocal microscopy (Zeiss LSM710; Carl Zeiss, Jena, Germany) using an excitation wavelength of $488 \mathrm{~nm}$ and emission wavelength of $>505 \mathrm{~nm}$, which represented the influx of the $\left[\mathrm{Ca}^{2+}\right] \mathrm{i}$.

OVA-induced asthma model of Balb/c mice. An asthma model of Balb/c mice was prepared as described previously (21-25). Briefly, female 6-8-week-old Balb/c mice were intraperitoneally injected with $100 \mu \mathrm{g}$ OVA in $0.2 \mathrm{ml}$ aluminium hydroxide (2\%) on days 1 and 8 , followed by aerosol challenge with $50 \mathrm{~g} / \mathrm{l}$ OVA for 20 min every day for 2 weeks. Control animals received $0.2 \mathrm{ml} 0.9 \%$ saline solution via intraperitoneal injection and were challenged with aerosolized $0.9 \%$ saline solution on the same days as the animals in the OVA group. In total of 45 mice were used in these experiments.

Assessment of bronchial Rrs by force oscillatory technique. Bronchial Rrs of the mice was measured by a force oscillatory technique using a computer-controlled FlexiVent system 

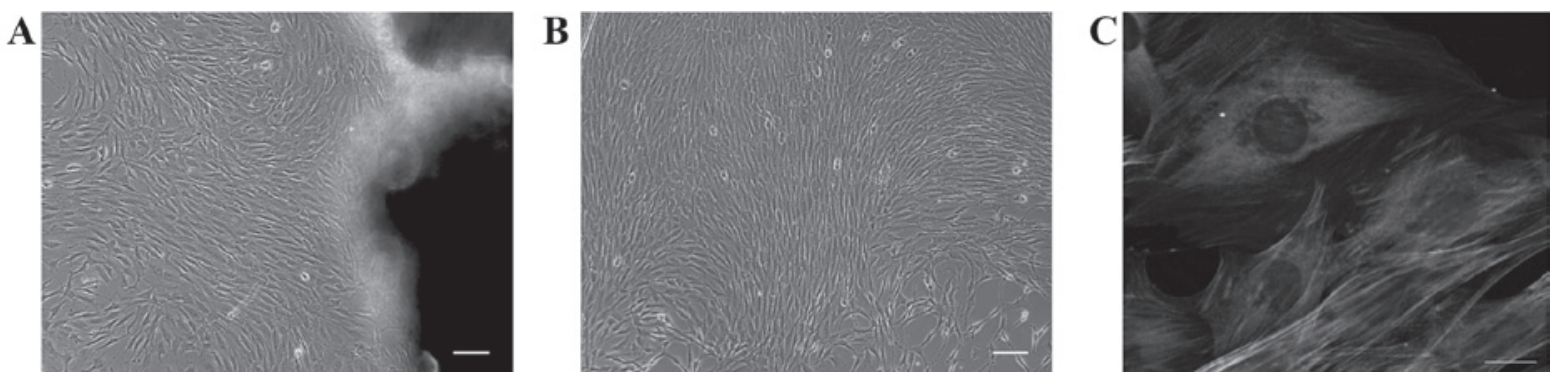

Figure 1. Characterization of the ASMCs from the Balb/c mouse. Phase-contrast microscopy images of ASMCs (A) freshly isolated from the trachealis muscle of Balb/c mice, and (B) after 8 days of culture in vitro (scale bars, $100 \mu \mathrm{m}$ ) with DMEM containing 10\% fetal bovine serum and $1 \%$ penicillin-streptomycin solution. (C) Microscopic image of the ASMCs with immunohistochemical staining for $\alpha$-SMA (scale bar, $20 \mu$ m). The nuclei were stained blue with 4',6-diamidino-2-phenylindole. AMSCs, airway smooth muscle cells; $\alpha$-SMA, $\alpha$-smooth muscle actin.

(SciReq, Montreal, QC, Canada) as described elsewhere (26). Briefly, the mice were anesthetized by intraperitoneal injection of pentobarbital sodium $(100 \mathrm{mg} / \mathrm{kg})$, intubated and connected to the adapter of the instrument. Next, the mice were first challenged with the bronchoconstrictor agent methacholine (Mch) at concentrations of $0,2,8,32$ or $64 \mathrm{mg} / \mathrm{ml}$ via inhalation, until the sustained Rrs was approximately 4-5-fold greater than the baseline value. The mice then inhaled naringin (15, 30 or $60 \mu \mathrm{g}$ ) or albuterol ( $3 \mu \mathrm{g})$, which was used as a conventional short acting $\beta_{2}$ agonist for comparison. Subsequently, Rrs was measured using the FlexiVent system every $30 \mathrm{sec}$ after atomization, for a duration of $5 \mathrm{~min}$. The results are expressed as the percentage of Rrs following treatment with the respective drug (Mch, Mch + naringin or Mch + albuterol) at each dose relative to the baseline value.

Statistical analysis. Dose response curves for $\left[\mathrm{Ca}^{2+}\right] \mathrm{i}$ were analyzed by iterative non-linear least squares fitting. Results from all studies were compared using one-way analysis of variance followed by post ad-hoc Student's t-tests for multiple comparisons using OriginPro 8.5.1 SR2 (OriginLab Corporation, Northampton, MA, USA), with $\mathrm{P}<0.05$ considered to indicate a statistically significant difference. Data are presented as the mean \pm standard error.

\section{Results}

Immunohistochemical characterization of the ASMCs cultured in vitro. Phase contrast microscopic images showed that the isolated cells had a long spindle shape and grew collectively into confluence with a 'peak-valley' structure, which are typical features of ASMCs in culture (Fig. 1A and B). Subsequent to a few cycles of purification, the cells were further authenticated by immunofluorescence appraisal method, which uses the fluorescently labeled $\alpha$-SMA antibodies to distinguish ASMCs. The results indicated that the purified cells exhibited uniform staining of $\alpha$-SMA with stress fiber structures (Fig. 1C). The purity of ASMCs was confirmed to be $\sim 99 \%$ based on the $\alpha$-SMA staining.

Effect of naringin on the traction force generated by the cultured ASMCs. The representative phase contrast images of two different single ASMCs attached to the surface of the flexible polyacrylamide gel before treatment are shown in Fig. 2A and B, respectively. Upon stimulation with histamine (a known contractile agonist of ASMCs), the two cells exerted traction force on the gel substrate, predominantly at the two ends of the cell and beneath the nucleus, as shown in Fig. 2C and D, respectively. However, the root mean square traction averaged over the entire cell projected area either increased or decreased progressively when the cell was exposed to further increasing doses of either histamine $(0.01,0.1$ and $1 \mu \mathrm{M})$ or naringin $(0.125,0.25,0.5$ and $1.0 \mathrm{mM})$, respectively, as shown in Fig. 2E (the lower left panel) and F (the lower right panel). Compared with the baseline traction force at $0 \mu \mathrm{M}$ histamine or $0 \mathrm{mM}$ naringin, the traction force generated by the ASMCs was either enhanced or reduced significantly when the cells were treated with either $1 \mu \mathrm{M}$ histamine or $1 \mathrm{mM}$ naringin, respectively $(\mathrm{P}<0.05)$.

Effect of naringin on $\left[\mathrm{Ca}^{2+}\right] \mathrm{i}$ in the cultured ASMCs. Fig. 3 shows representative fluorescence microscopy images (Fig. 3A) and fluorescence intensity time-course traces (Fig. 3B) of the cultured AMSCs in response to treatment with naringin. In the fluorescence microscopy images, a single cell can be seen responding to the addition of naringin $(1 \mathrm{mM})$ as the fluorescence intensity of the calcium ion specific dye (Fluo-4 AM) inside the cell increased following treatment. Prior to naringin addition $(0 \mathrm{sec})$, the fluorescence was almost invisible, whereas a bright level of fluorescence was observed at $33 \mathrm{sec}$ after adding naringin (Fig. 3A). The time-course traces of the changing overall fluorescence intensity inside the cell further confirmed the response and the dose-dependent effect of the ASMCs exposure to naringin (Fig. 3B). In the absence of naringin, the cell exhibited a stable baseline level $\left(\mathrm{F}_{0}\right)$ of the $\left[\mathrm{Ca}^{2+}\right] \mathrm{i}$, as determined by the cell's overall fluorescence intensity. When naringin $(0,0.25,0.5$ or $1.0 \mathrm{mM})$ was added to the culture medium at the time point of $20 \mathrm{sec}$, the $\left[\mathrm{Ca}^{2+}\right] \mathrm{i}$ of the cell increased rapidly, reaching a peak value at $\sim 30 \mathrm{sec}$ and then decreasing towards the baseline. Although the pattern of the transient response was similar in all cases, the magnitude of the response seemed to be dependent on the dose of naringin at which the cell was exposed to. After normalizing to the baseline value $\left(\mathrm{F}_{0}\right)$ to eliminate uncertainty due to differences between individual cells and dyeing processes, naringin at the concentration as low as $0.25 \mathrm{mM}$ was found to already induce a marked response on the $\left[\mathrm{Ca}^{2+}\right] \mathrm{i}$ in the cell. As the concentration of naringin increased further to 0.5 and $1.0 \mathrm{mM}$, the peak value of the $\left[\mathrm{Ca}^{2+}\right]$ i response increased progressively and reached $\sim 4$-fold of the baseline level at $1.0 \mathrm{mM}$. 
A
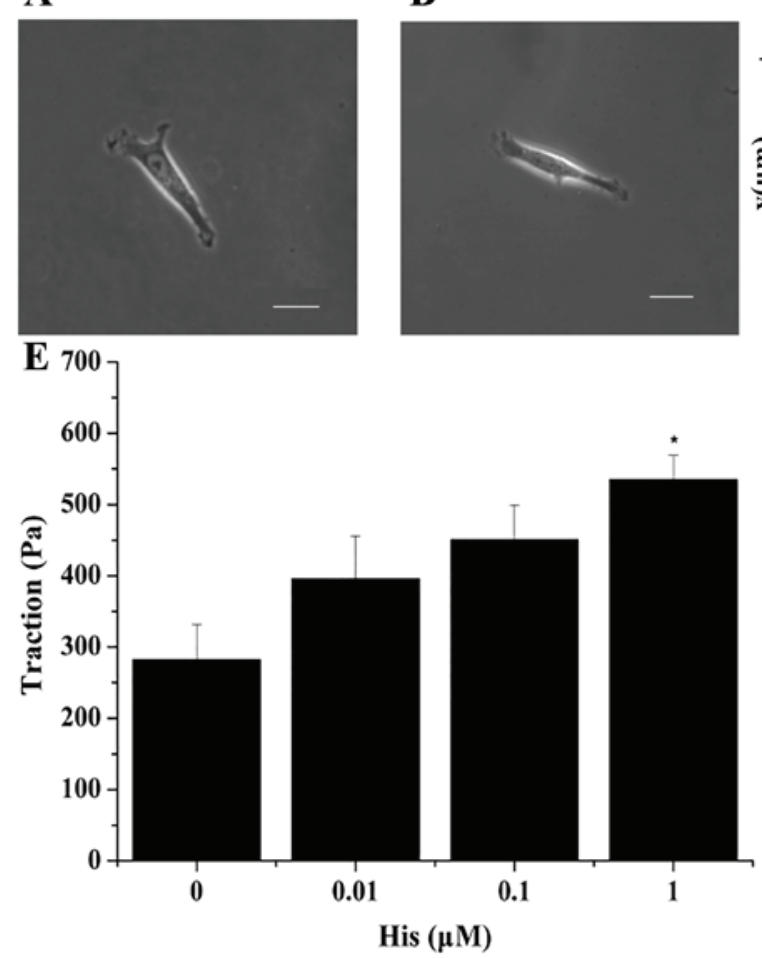

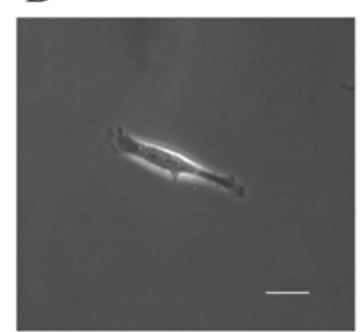

His $(\mu \mathrm{M})$
C

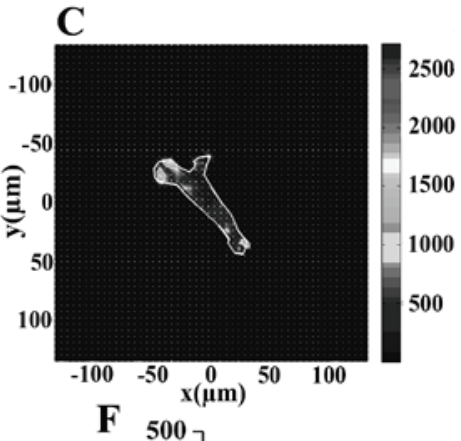

D

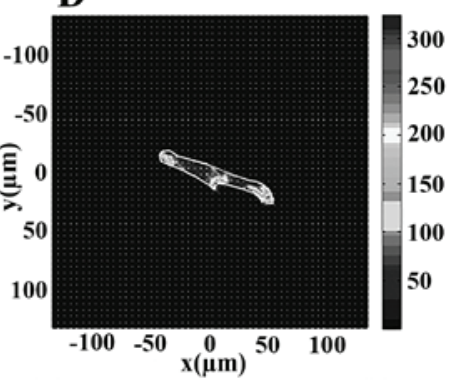

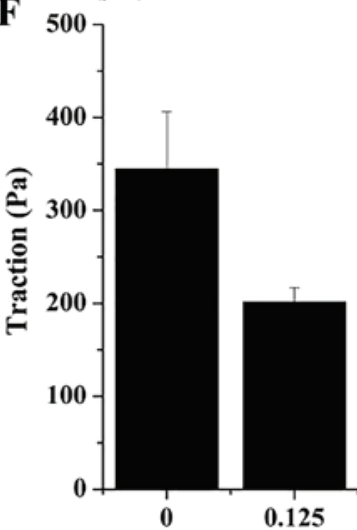

0.125

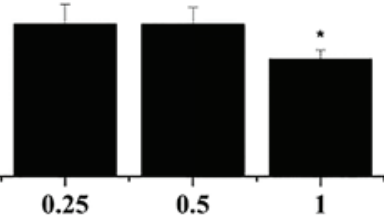

Naringin $(\mathbf{m M})$

Figure 2. Traction force generated by the cultured ASMCs in response to treatment with histamine or naringin. (A and B) Representative phase-contrast microscopic images, and (C and D) map of the traction force of a single ASMC cultured on polyacrylamide substrate following treatment with (A and C) histamine and ( $\mathrm{B}$ and $\mathrm{D}$ ) naringin, (the grayscale indicates the magnitude of traction force in Pa). The calculated mean traction force of the ASMCs in response to treatment with $(\mathrm{E})$ histamine $(0,0.01,0.1$ and $1 \mu \mathrm{M})$ or $(\mathrm{F})$ naringin $(0,0.125,0.25,0.5$ and $1 \mathrm{mM})$. Data are presented as the mean \pm standard error $(\mathrm{n}=4-6 \mathrm{cells})$. Scale bar $=20 \mu \mathrm{m} .{ }^{*} \mathrm{P}<0.05$ vs. $0 \mathrm{mM}$. AMSC, airway smooth muscle cell.
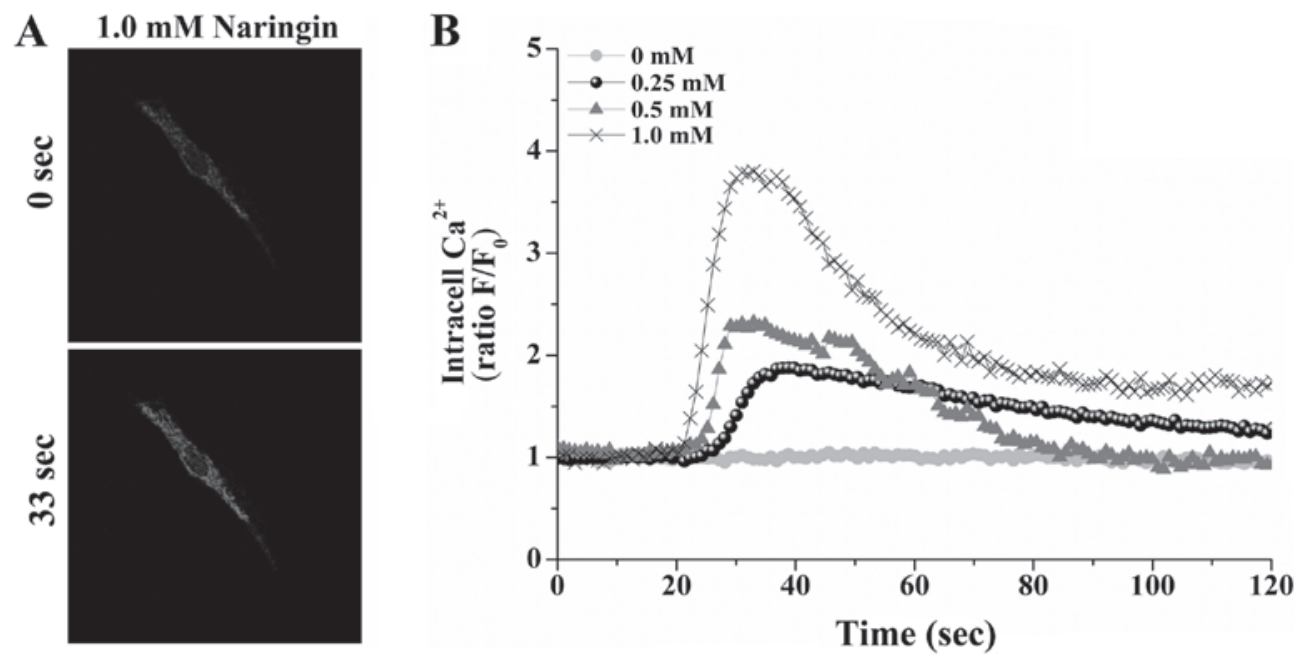

Figure 3. $\left[\mathrm{Ca}^{2+}\right]$ i signaling in the cultured ASMCs in response to treatment of naringin. An ASMC was stained with Fluo-4 AM, a fluorescent dye that specifically binds to intracellular calcium ions in order to visualize the $\left[\mathrm{Ca}^{2+}\right]$ i by fluorescence microscopy imaging, and was quantified by the alteration in fluorescence intensity of the cell. (A) Representative sequential fluorescence microscopic images of a single ASMC prior to (0 sec) and following ( 33 sec) exposure to $1.0 \mathrm{mM}$ naringin. The cell fluorescence intensity markedly increased at $33 \mathrm{sec}$ after exposure to naringin as compared with that at 0 sec, indicating activation of $\left[\mathrm{Ca}^{2+}\right] \mathrm{i}$ in the cell. (B) Dose-dependent time courses of transient $\left[\mathrm{Ca}^{2+}\right]$ i signals in the ASMC prior to and following treatment with naringin. AMSC, airway smooth muscle cell; $\left[\mathrm{Ca}^{2+}\right] \mathrm{i}$, intracellular calcium flux; Fluo-4 AM, Fluo-4 acetoxymethyl ester.

Characterization of the OVA-induced asthma model of Balb/c mice. Fig. 4 displays the test results of Rrs increase (as the \% of the baseline value) in response to Mch stimulation in the normal (control) and OVA-induced asthma model (OVA) of $\mathrm{Balb} / \mathrm{c}$ mice. When challenged with increasing concentration of Mch $(0,2,8,32$ and $64 \mathrm{mg} / \mathrm{ml})$, the Rrs measured by the invasive FlexiVent system increased progressively compared with the corresponding baseline values. However, the increase was greater in OVA-treated mice than in the control mice, and the difference of Rrs between the OVA and control groups 


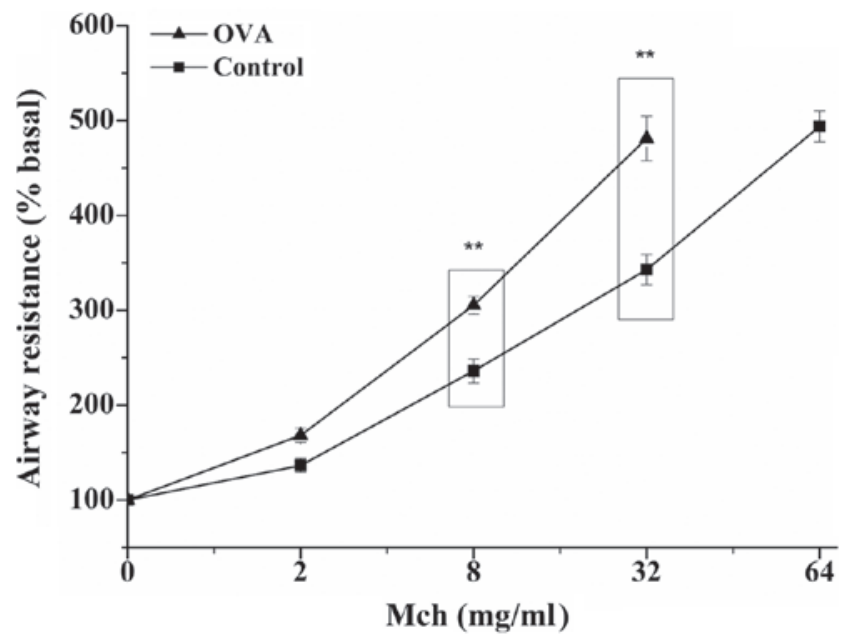

Figure 4. Rrs increase in response to Mch stimulation in normal or OVA-induced asthma Balb/c mice. Rrs is presented as the percentage of the baseline value of the normal control or OVA-treated Balb/c mice when challenged with increasing concentrations of Mch (control: 0, 2, 8 and $32 \mathrm{mg} / \mathrm{ml}$ Mch; OVA: 0, 2, 8, 32 and $64 \mathrm{mg} / \mathrm{ml} \mathrm{Mch).} \mathrm{Data} \mathrm{are} \mathrm{pre-}$ sented as the mean \pm standard error $(n=24)$. Rrs, airway resistance; Mch, methacholine; OVA, ovalbumin.

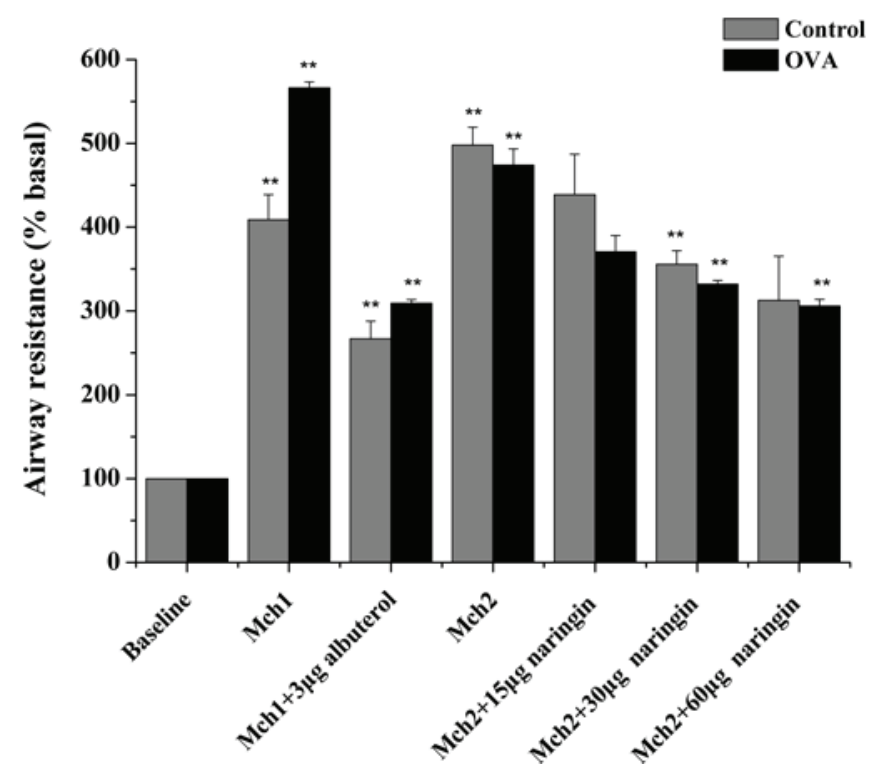

Figure 5. Effect of naringin on attenuation of Rrs in Mch-challenged Balb/c mice. Rrs was measured in the normal (control) or OVA-induced asthma Balb/c mice prior to challenge (baseline) and following challenge with Mch. To ensure comparability, the normal and OVA-treated mice were challenged with 64 and $32 \mathrm{mg} / \mathrm{ml} \mathrm{Mch,} \mathrm{respectively,} \mathrm{to} \mathrm{induce} \mathrm{a} \mathrm{4-5-fold} \mathrm{increase} \mathrm{in} \mathrm{Rrs}$ Two different groups of Mch-challenged mice, Mch1 and Mch2, were further treated with albuterol $(3 \mu \mathrm{g})$ or naringin $(15,30$ and $60 \mu \mathrm{g})$, respectively. The Rrs was normalized against the baseline value in each group, and the normalized Rrs of albuterol-treated group (Mch1 $+3 \mu \mathrm{g}$ albuterol, control or OVA) was compared to that of the corresponding Mch1 group. The normalized Rrs of naringin-treated group (Mch2 + 15/30/60 $\mu \mathrm{g}$ naringin, control and OVA) was compared to that of the corresponding Mch2 group, respectively. Data are presented as the mean \pm standard error $(n=5-6) .{ }^{* *} \mathrm{P}<0.01$ vs. Mch1/Mch2 group. Mch, methacholine; OVA, ovalbumin; Rrs, airway resistance.

was statistically significant $(\mathrm{P}<0.01$; Fig. 4) when the Mch concentration was increased to $8 \mathrm{mg} / \mathrm{ml}$ and higher. The threshold of 4- to 5-fold increase in Rrs is usually required for the maximum bronchial constriction induced by Mch in the study of AHR (10). In the present study, the maximum dose of Mch to reach this threshold was $64 \mathrm{mg} / \mathrm{ml}$ in the control group and $32 \mathrm{mg} / \mathrm{ml}$ in the OVA group, as shown in Fig. 4. The OVA-treated mice also exhibited other hallmarks of asthma, including airway inflammation and remodeling (data not shown). These test results verified that the OVA-treated mice presented the characteristics, particularly the occurrence of AHR, that are observed in allergic asthma, thus it was suitable to be used in the evaluation of naringin's efficacy in the relaxation of ASMCs.

Effect of naringin on Rrs of normal or OVA-induced asthma Balb/c mice. To evaluate the in vivo effect of naringin on bronchodilation in asthmatic mice, the Rrs of normal (control) or OVA-treated (OVA) Balb/c mice was measured. Mice were first challenged with Mch to induce maximum airway contraction (4-5-fold increase of Rrs over the baseline value), and then atomized with naringin $(15,30$ or $60 \mu \mathrm{g})$ via inhalation. As a positive control, the mice were atomized with albuterol $(3 \mu \mathrm{g})$, a common $\beta_{2}$-adrenergic agonist used as a bronchodilator for treating asthma.

As shown in Fig. 5, when challenged with Mch at a concentration of $64 \mathrm{mg} / \mathrm{ml}$ in the control and $32 \mathrm{mg} / \mathrm{ml}$ in the OVA mice, Rrs in the two groups increased significantly $\left(\mathrm{P}=3.39 \times 10^{-6}\right.$ vs. baseline in the control group; $\mathrm{P}=8.38 \times 10^{-7}$ vs. baseline in the OVA group) to up to $\sim 5$-fold of the baseline value. Following the Mch challenge, atomization inhalation of albuterol $(3 \mu \mathrm{g})$ effectively reduced $\operatorname{Rrs}\left(\mathrm{P}=3.38 \times 10^{-5}\right.$ vs. Mch in the control group; $\mathrm{P}=1.65 \times 10^{-5}$ vs. Mch in the OVA group) to a considerably lower level in the control and OVA groups, which was expected since albuterol is a well-known bronchodilator. More importantly, atomization inhalation of naringin also caused a reduction of Rrs in the control and OVA groups in a progressive manner as the concentration of naringin increased from 15 to $60 \mu \mathrm{g}$. Specifically, inhalation of $3 \mu \mathrm{g}$ albuterol resulted in a decrease of the Rrs by $35 \pm 3.8 \%$ in the normal mice and $45 \pm 1.8 \%$ in the OVA-treated mice, while inhalation of $60 \mu \mathrm{g}$ naringin led to a decrease in the Rrs by $38 \pm 4.4 \%$ in the normal mice and $36 \pm 1.4 \%$ in the OVA-treated mice. Further increase of naringin concentration to $60 \mu \mathrm{g}$ caused additional decrease of Rrs in the OVA-treated mice, however this was not observed in the normal group.

\section{Discussion}

The primary finding of the present study was that naringin, as a widely available bitter substance and flavanone, was able to effectively relax ASMCs both in vitro and in vivo. This effect was manifested by the reduction of traction force and induction of $\left[\mathrm{Ca}^{2+}\right] \mathrm{i}$ in cultured ASMCs due to exposure to naringin in solution, and by the attenuation of the Mch-induced Rrs increase in normal mice and in an OVA-induced asthma model of Balb/c mice upon inhalation of naringin in aerosol form. However, the extent of naringin's effect on the relaxation of the cultured ASMCs or bronchial airways in mice was dependent on the dose of naringin to which the cultured cells or mice were exposed. In the cultured ASMCs, the presence of naringin in the culture medium at increasing concentration up to $1.0 \mathrm{mM}$ caused the traction force to decrease, and $\left[\mathrm{Ca}^{2+}\right] \mathrm{i}$ to increase progressively. In the normal and OVA-treated mice, 
inhalation of naringin at an increasing dose up to $60 \mathrm{mg}$ caused the Mch-contracted bronchial airways to dilate progressively, as measured by the progressive reduction of Rrs. However, the bronchodilatory effect of naringin appeared to be marginally greater in the OVA-treated mice compared with that in the normal mice, suggesting differential efficacy of naringin for dilation of bronchial airways with or without AHR.

In the present study, Fourier transform traction cytometry was used to quantify the ability of ASMCs to generate traction force (equivalent to cell contraction), which has been widely used as an assay to evaluate contraction/relaxation of ASMCs during stimulation with a contractile agonist, such as histamine, or a relaxing agonist, such as isoproterenol $(17,18)$. Regarding targeting the receptor TAS2R of ASMCs for relaxation, it has been reported previously that a prototypic TAS2R agonist, namely quinine hydrochloride, can reduce the average traction force generated by ASMCs in a dose-dependent manner, which is mediated by the activation of the four most highly expressing TAS2Rs in human ASMCs (which are TAS2R4/10/14/31) (10,27). The current study demonstrated that naringin, a naturally abundant bitter substance, was also able to increasingly reduce the traction force generated by ASMCs when the cells were treated with an increasing dose of naringin $(0.125,0.25,0.5$ and $1.0 \mathrm{mM})$, thus to the best of our knowledge, providing for the first time, evidence that naringin exerts a relaxation effect on airway smooth muscle at the cell level.

In comparison to other bitter taste compounds, naringin appears to be remarkably potent in inducing ASMC relaxation. For instance, at the same concentration of $1 \mathrm{mM}$, naringin caused a reduction of ASMC traction force by $\sim 64 \%$ (from 350 to $225 \mathrm{~Pa}$ ), whereas quinine reduced it by only $31 \%$ (from 325 to $225 \mathrm{~Pa}$ ) (28), while saccharin and chloroquine reduced cell stiffness (another estimate of ASMC relaxation) by $40-50 \%$ (10). A previous study observed that bitter substances, such as saccharin or quinine, induce relaxation of the ASMC by mediating transient increase of $\left[\mathrm{Ca}^{2+}\right] \mathrm{i}$ in the cell, which can be observed by fluorescent laser scanning confocal microscopy while using calcium ion specific dye Fluo-4 AM to label the intracellular calcium ions (10). In the present study, we used the same method to elucidate whether naringin also induces relaxation of ASMCs via mediation of $\left[\mathrm{Ca}^{2+}\right] \mathrm{i}$ in the cell. Naringin was found to mediate the increase of $\left[\mathrm{Ca}^{2+}\right] \mathrm{i}$ in the cell as the concentration of naringin increased from 0.25 to $1.0 \mathrm{mM}$. The general trend of the $\left[\mathrm{Ca}^{2+}\right]$ i response to naringin stimulation was consistent with the effect induced by other well-known bitter tastants, such as quinine (28), saccharin and chloroquine (10). Nevertheless, the magnitude of $\left[\mathrm{Ca}^{2+}\right] \mathrm{i}$ response to naringin treatment (2.75-fold change at a concentration of $1 \mathrm{mM}$ ) was greater as compared with that observed for other bitter tastants $(1 \mathrm{mM})$, including saccharin (1.87-fold) (10), chloroquine (1.75-fold) (10) and quinine (0.75-fold) (28), further demonstrating the potency of naringin as an ASMC relaxant among the tested bitter taste compounds. Furthermore, the change in $\left[\mathrm{Ca}^{2+}\right]$ i was also closely associated with the change in traction force generation (relaxation) of the ASMCs in response to naringin stimulation, similar as in the case of ASMCs stimulated by quinine (2).

TAS2Rs and agonists are known to be coupled to evoke $\left[\mathrm{Ca}^{2+}\right] \mathrm{i}$ signal in specialized taste cells of the tongue, and this signal is also found in the functioning of known bronchoconstrictive $\mathrm{G}$ protein coupled receptors (GPCRs), such as those for histamine, acetylcholine and bradykinin (29). According to this effect, it can be assumed that bitter agonists would cause bronchoconstriction, as opposed to the experimental results so far indicating that all bitter agonists are bronchodilators. This seeming contradiction is resolved as further studies have revealed the difference between the $\left[\mathrm{Ca}^{2+}\right] \mathrm{i}$ signaling in response to GPCR agonist or TAS2R agonist. GPCR agonists, such as histamine, mediate $\left[\mathrm{Ca}^{2+}\right] \mathrm{i}$ increase throughout the entire cell by membrane depolarization and thus induce contraction of the ASMCs. By contrast, TAS2R agonists, such as quinine hydrochloride, mediate a localized $\left[\mathrm{Ca}^{2+}\right]$ i response at the cell membrane, which expands large-conductance $\mathrm{Ca}^{2+}$-activated $\mathrm{K}^{+}$channels, and thus leads to membrane hyperpolarization and relaxation of the ASMC (10,30-33). Based on these previous studies and the similarity between the bitter tastants, it may be reasonable to attribute the naringin-induced relaxation of ASMCs in the current study to the cell membrane hyperpolarization due to localized $\left[\mathrm{Ca}^{2+}\right] \mathrm{i}$ response, although direct evidence of this underlying mechanism is yet to be seen in future studies.

In addition to the relaxation effect of naringin on ASMCs cultured in vitro, we further evaluated the bronchodilatory effect of naringin on mice since the in vivo results would be much more relevant to the requirement of clinical treatment. For this purpose, normal or OVA-induced asthma Balb/c mice were used. The establishment of an asthma model in the mice was characterized and verified by presentation of the cardinal hallmarks associated with allergic asthma, including AHR, as measured by the excessive increase in Rrs upon Mch stimulation. The results indicated that atomization inhalation of naringin $(15,30$ and $60 \mu \mathrm{g})$ attenuated the Mch-induced increase of Rrs in a dose-dependent manner in the normal and OVA-treated mice. Furthermore, the naringin-induced bronchodilation in the OVA-treated mice continued to increase until the dose reached $60 \mathrm{mg}$, whereas that in the normal mice had approached the maximum effect at the dose of $30 \mathrm{mg}$. A previous study by Deshpande et al (10) identified that inhaled aerosolized quinine $(150 \mu \mathrm{g})$ decreased Rrs from the Mch-challenged level in normal and OVA-treated mice by 53 and $50 \%$, respectively. In the present study, inhaled aerosolized naringin $(60 \mu \mathrm{g})$ decreased Rrs from the Mch-challenged level in normal and OVA-treated mice by 38 and 36\%, respectively (Fig. 5). In both the present and previous study, the bitter tastant (quinine or naringin) caused similar extents of airway relaxation in normal and sensitized mice, suggesting that the expression of TAS2Rs may be regulated during disease progression.

It should be noted that the maximum dose of naringin used in the current study was limited to $60 \mu \mathrm{g}$ due to its solubility. Therefore, the difference in airway relaxation extent of the mice exposed to quinine (28) and naringin does not mean that quinine was more potent compared with naringin, since the two compounds were delivered at different doses (150 vs. $60 \mu \mathrm{g}$, respectively). On the contrary, it was demonstrated that in vitro and at the same dose of $1 \mathrm{mM}$, naringin was more potent in inducing relaxation of cultured ASMCs when compared with other known bitter tastants, including quinine, saccharin and chloroquine, as discussed earlier. It 
is also noted that naringin caused in vivo airway relaxation with an extent that was $68 \%$ of that caused by $150 \mu \mathrm{g}$ quinine, although the naringin dose was only $40 \%$ of the $150 \mu \mathrm{g}$ quinine (28). This indicates that naringin may be more potent than quinine in inducing in vivo airway relaxation if delivered at the same dose.

It is also important to note that naringin and quinine are two bitter taste compounds with similar features of the chemical structure. Specifically, they both have aromatic rings and hydroxyl groups, which may act on the same type of TAS2Rs and the associated signal pathways $(27,34)$. Therefore, it is not surprising that inhalation of naringin at the dose of $60 \mu \mathrm{g}$ and quinine at $150 \mu \mathrm{g}$ (10) caused bronchodilation to a similar extent. However, such level of bronchodilation by the bitter tastants (60 mg naringin; $150 \mathrm{mg}$ quinine) was equivalent to that caused by $3 \mu \mathrm{g}$ albuterol, which is a compound commonly used in clinical treatment. This comparison may suggest that naringin, as well as quinine, may be one order of magnitude less potent compared to albuterol as bronchodilators. However, $\beta_{2}$-adrenergic agonists, like albuterol, are known to be associated with several side effects, such as tachyphylaxis, individual variations in responsiveness and safety concerns, which makes them less effective for long-term treatment. One should also consider that there are thousands of known bitter substances readily available for screening as potential bronchodilators. Among them, there are possibly certain compounds that can stimulate TAS2Rs at extremely low concentrations, and therefore it is likely that highly potent bronchodilators will be identified in the future by following the same strategy as in the present study. At the same time, two recent publications have investigated the therapeutic potential of naringin in treating asthma $(35,36)$. These two studies have mainly evaluated the effect of naringin on the alleviation of asthma symptoms, including airway inflammation, coughing and AHR, from the phenomenological point of view using in vivo animal studies $(35,36)$. While confirming the effect of naringin on airway inflammation and AHR, the present study further elucidated the underlying mechanisms through which naringin reduces AHR particularly from ASMC biomechanics aspect, using both an in vivo animal model and in vitro cultured cells. Finally, it is worth mentioning that the current study was limited to the assessment of only the traction force in cultured ASMCs and Rrs in Balb/c mice. In addition, small numbers of sample populations, unoptimized drug formulation and delivery, and a selective animal model of asthma were used in the present study. These limitations may raise questions regarding the real potential and value of naringin in the clinical treatment of human asthma, and therefore the current findings need to be further investigated in vitro and in vivo with human cells and tissues in the future.

In conclusion, the present study demonstrated that naringin, one of the most common TAS2R agonists, was able to in vitro relax ASMCs in culture and in vivo dilate contracted bronchial airways in mice. These results confirm that this TAS2R may be a novel target for bronchodilation in obstructive airway diseases, such as asthma. More importantly, it was verified that naringin is a promising drug candidate of effective, safe and inexpensive bronchodilator for asthma therapy, at least in the current experimental settings. Finally, such evaluation can also be extended to screen the vast bank of natural bitter substances, which may lead to the discovery of more potent bronchodilators.

\section{Acknowledgements}

The authors would like to thank Dr Wenxian Gu (Changzhou No. 2 People's Hospital, Changzhou, China) for their assistance in examination of the mouse lung pathology and histology. This study was supported by the National Natural Science Foundation of China (grant nos. 11532003, 11402037 and 11172340), the Office for Talent Recruitment of Jiangsu Province, China (Double Talent Plan grant no. SRCB-2012-39), and the Bureau of Science and Technology of Changzhou Municipality, Jiangsu Province, China (Key Laboratory grant no. CM20133005).

\section{References}

1. Alotaibi, GhaziAbdulrahman: Asthma control and self-management: The role of asthma education. Saudi J Health Sci 4: 16-22, 2015.

2. Al Frayh AR, Shakoor Z, Gad El Rab MO and Hasnain SM: Increased prevalence of asthma in Saudi Arabia. Ann Allergy Asthma Immunol 86: 292-296, 2001.

3. Centers for Disease Control and Prevention (CDC): 2012 National Health Interview Survey (NHIS) Data. http://www.cdc. gov/asthma/nhis/2012/data.htm.

4. Albazzaz MK and Patel KR: Effect of azelastine on bronchoconstriction induced by histamine and leukotriene $\mathrm{C} 4$ in patients with extrinsic asthma. Thorax 43: 306-311, 1988.

5. Fredberg JJ: Bronchospasm and its biophysical basis in airway smooth muscle. Respir Res 5: 2, 2004.

6. Hershenson MB, Brown M, Camoretti-Mercado B and Solway J: Airway smooth muscle in asthma. Annu Rev Pathol 3: 523-555, 2008.

7. King GG, Paré PD and Seow CY: The mechanics of exaggerated airway narrowing in asthma: The role of smooth muscle. Respir Physiol 118: 1-13, 1999.

8. Weaver J: How bitter medicine could clear up asthma. PLoS Biol 11: e1001500, 2013.

9. Grassin-Delyle S, Abrial C, Fayad-Kobeissi S, Brollo M, Faisy C, Alvarez JC, Naline E and Devillier P: The expression and relaxant effect of bitter taste receptors in human bronchi. Respir Res 14: 134, 2013.

10. Deshpande DA, Wang WC, McIlmoyle EL, Robinett KS, Schillinger RM, An SS, Sham JS and Liggett SB: Bitter taste receptors on airway smooth muscle bronchodilate by localized calcium signaling and reverse obstruction. Nat Med 16: 1299-1304, 2010.

11. Xie R, Wen S, Li Y, Zuo C and Zhang J: Study on the antiinflammation and analgesia of naringin. J Hunan Normal Univ (Med Sci) 8: 5-8,12, 2011.

12. Luo YL, Zhang CC, Li PB, Nie YC, Wu H, Shen JG and Su WW: Naringin attenuates enhanced cough, airway hyperresponsiveness and airway inflammation in a guinea pig model of chronic bronchitis induced by cigarette smoke. Int Immunopharmacol 13: 301-307, 2012.

13. Hirst SJ: Airway smooth muscle cell culture: Application to studies of airway wall remodelling and phenotype plasticity in asthma. Eur Respir J 9: 808-820, 1996.

14. Durand-Arczynska W, Marmy N and Durand J: Caldesmon, calponin and alpha-smooth muscle actin expression in subcultured smooth muscle cells from human airways. Histochemistry 100: 465-471, 1993.

15. Dembo M and Wang YL: Stresses at the cell-to-substrate interface during locomotion of fibroblasts. Biophys J 76: 2307-2316, 1999.

16. Pelham RJ Jr and Wang Y: Cell locomotion and focal adhesions are regulated by substrate flexibility. Proc Natl Acad Sci USA 94: 13661-13665, 1997.

17. Wang N, Tolić-Nørrelykke IM, Chen J, Mijailovich SM, Butler JP, Fredberg JJ and Stamenović D: Cell prestress. I. Stiffness and prestress are closely associated in adherent contractile cells. Am J Physiol Cell Physiol 282: C606-C616, 2002. 
18. Tolić-Nørrelykke IM, Butler JP, Chen J and Wang N: Spatial and temporal traction response in human airway smooth muscle cells. Am J Physiol Cell Physiol 283: C1254-C1266, 2002.

19. Yang XR, Lin MJ, Yip KP, Jeyakumar LH, Fleischer S, Leung GP and Sham JS: Multiple ryanodine receptor subtypes and heterogeneous ryanodine receptor-gated $\mathrm{Ca}^{2+}$ stores in pulmonary arterial smooth muscle cells. Am J Physiol Lung Cell Mol Physiol 289: L338-L348, 2005.

20. Remillard CV, Zhang WM, Shimoda LA and Sham JSK: Physiological properties and functions of $\mathrm{Ca}(2+)$ sparks in rat intrapulmonary arterial smooth muscle cells. Am J Physiol Lung Cell Mol Physiol 283: L433-L444, 2002.

21. Chen H, Cheng S, Wang A, Bunjhoo H, Cao Y, Xie J, Wang C, $\mathrm{Xu}$ Y and Xiong W: IL-21 does not involve in OVA-induced airway remodeling and chronic airway inflammation. Int J Clin Exp Med 8: 10640-10645, 2015.

22. Zhang CH, Li Y, Zhao W, Lifshitz LM, Li H, Harfe BD, Zhu MS and ZhuGe R: The transmembrane protein $16 \mathrm{~A} \mathrm{Ca}(2+)$-activated Cl- channel in airway smooth muscle contributes to airway hyperresponsiveness. Am J Respir Crit Care Med 187: 374-381, 2013.

23. Jie Z, Jin M, Cai Y, Bai C, Shen Y, Yuan Z, Hu Y and Holgate S: The effects of Th2 cytokines on the expression of ADAM33 in allergen-induced chronic airway inflammation. Respir Physiol Neurobiol 168: 289-294, 2009.

24. Song A, Liao Q, Li J, Lin F, Liu E, Jiang X and Deng L: Chronic exposure to sulfur dioxide enhances airway hyperresponsiveness only in ovalbumin-sensitized rats. Toxicol Lett 214: 320-327, 2012.

25. Zhang YJ, Wang YN, Ding YJ, He LY, Liu X and Kang QZ: Establishment of bronchial asthma model induced with OVA. Henan Medical Research 21: 268-270, 2012.

26. Jonasson S, Hjoberg J, Hedenstierna $G$ and Basu $S$ : Allergen-induced formation of F2-isoprostanes in a murine asthma model identifies oxidative stress in acute airway inflammation in vivo. Prostaglandins Leukot Essent Fatty Acids 80: 1-7, 2009.

27. Meyerhof W, Batram C, Kuhn C, Brockhoff A, Chudoba E, Bufe B, Appendino G and Behrens M: The molecular receptive ranges of human TAS2R bitter taste receptors. Chem Senses 35 157-170, 2010.
28. Zeng HL, Wang Y, Luo MZ, Shi XH, Lu Y, Pan Y and Deng LH: Bitter taste receptor agonist (Quinine) induces traction force reduction and calcium flux increase in airway smooth muscle cells from ovalbumin-sensitized and challenged rats. J Adv Biomed Eng Technol 2: 20-27, 2015.-

29. Billington CK and Penn RB: Signaling and regulation of $\mathrm{G}$ protein-coupled receptors in airway smooth muscle. Respir Res 4: 2, 2003.

30. Pulkkinen V, Manson ML, Säfholm J, Adner M and Dahlén SE: The bitter taste receptor (TAS2R) agonists denatonium and chloroquine display distinct patterns of relaxation of the guinea pig trachea. Am J Physiol Lung Cell Mol Physiol 303: L956-L966, 2012.

31. An SS, Wang WC, Koziol-White CJ, Ahn K, Lee DY, Kurten RC, Panettieri RA Jr and Liggett SB: TAS2R activation promotes airway smooth muscle relaxation despite $\beta(2)$-adrenergic receptor tachyphylaxis. Am J Physiol Lung Cell Mol Physiol 303: L304-L311, 2012.

32. Townsend EA, Yim PD, Gallos G and Emala CW: Can we find better bronchodilators to relieve asthma symptoms? J Allergy (Cairo) 2012: 321949, 2012.

33. Clifford RL and Knox AJ: Future bronchodilator therapy: A bitter pill to swallow? Am J Physiol Lung Cell Mol Physiol 303: L953-L955, 2012.

34. Behrens M, Brockhoff A, Kuhn C, Bufe B, Winnig M and Meyerhof W: The human taste receptor hTAS2R14 responds to a variety of different bitter compounds. Biochem Biophys Res Commun 319: 479-485, 2004.

35. Guihua X, Shuyin L, Jinliang G and Wang S: Naringin protects ovalbumin-induced airway inflammation in a mouse model of asthma. Inflammation 39: 891-899, 2016.

36. Jiao HY, Su WW, Li PB, Liao Y, Zhou Q, Zhu N and He LL: Therapeutic effects of naringin in a guinea pig model of ovalbumin-induced cough-variant asthma. Pulm Pharmacol Ther 33: 59-65, 2015. 